\title{
Behavior of thiosemicarbazones derived from some terpenones under acetylating conditions
}

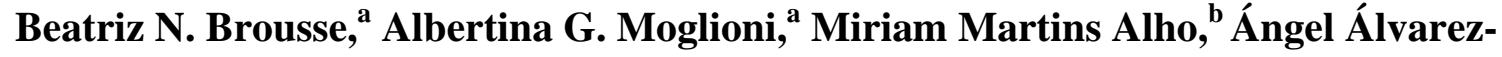 \\ Larena, ${ }^{c}$ Graciela Y. Moltrasio, ${ }^{* a}$ and Norma B. D'Accorso ${ }^{b}$ \\ ${ }^{a}$ Dpto. de Qca. Orgánica. Facultad de Farmacia y Bioquímica. ${ }^{b}$ Dpto. de Qca. Orgánica. \\ Facultad de Ciencias Exactas y Naturales. Universidad de Buenos Aires. Argentina \\ ${ }^{c}$ Unitat de Cristal.lografia, Universitat Autònoma de Barcelona, 08193 Bellaterra, Barcelona, \\ Spain \\ E-mail: angel.alvarez@uab.es
}

(received 13 Jun 2002; accepted 03 Sep 2002; published on the web 11 Sep 2002)

\begin{abstract}
Preparation of chiral heterocyclic compounds of the thiadiazoline types, starting from natural terpenones such as fenchone, camphor and menthone, is described. Stereochemical assignment of the compounds synthesized was performed by NMR spectroscopy and X-ray analysis.
\end{abstract}

Keywords: Asymmetric spiro-heterocyclic compounds, terpenones, thiosemicarbazones, thiadiazolines

\section{Introduction}

Certain organic compounds of natural origin are the primary source of chirality in organic synthesis and are used to prepare other chiral compounds of interest. Among the various types of natural chiral products, carbohydrates and amino acids have been successfully employed, but terpenes have received less attention. In spite of their high enantiomeric purity and their availability, the lack of functional groups in terpenes makes them less attractive as chiral auxiliaries. Although this is true for the natural terpenes as hydrocarbons, it is not the case for terpenones and for terpenols which can be useful thanks to their functionality, to their ready availability and to their satisfactory enantiomeric excess. ${ }^{1}$

Recently, we have reported a very simple method for preparing thiadiazolines by cyclization under acetylating conditions of the corresponding thiosemicarbazones of several achiral aromatic ketones $^{2}$ (Scheme 1). 

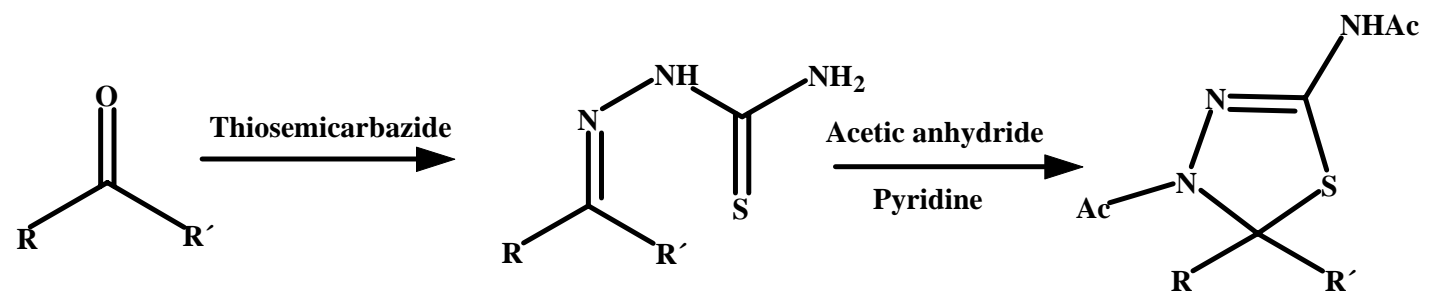

Scheme 1. General pathway for thiadiazolines's synthesis.

A considerable number of thiosemicarbazone derivatives have been reported as antibacterial, antiviral and antiproliferative compounds. In particular, certain thiosemicarbazones showed a selective inhibition of herpes simplex virus (HSV) infection in vitro ${ }^{3 a}$ and also thiosemicarbazones were active inhibitors of in vivo HSV genital infection. ${ }^{3 b}$ The effect of thiosemicarbazones against human immunodeficiency virus (HIV) was also reported on the HIV structural protein synthesis. ${ }^{3 \mathrm{c}}$ Thiadiazolines were screened only for their antibacterial activity, ${ }^{3 \mathrm{~d}}$ but their antiviral properties have not been investigated.

We have also described the preparation of cyclization products (via the corresponding thiosemicarbazones), starting from carbonyl compounds derived from carbohydrates where the preferential attack has been observed by one of the faces of the thiosemicarbazone azomethine carbon atom, to render separable diastereoisomers or a single isomer. ${ }^{4}$ Here we report the synthesis of new chiral thiadiazolines derived from natural monoterpenones.

In order to determine the influence of the terpene ketone structure on diastereoselection in the heterocyclization reaction, bicyclic (fenchone 1 and camphor 2) and monocyclic (menthone 3) monoterpenones were chosen (see Figure 1).

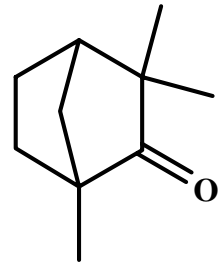

1

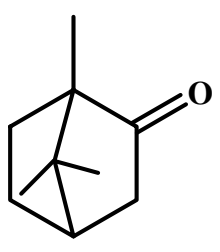

2

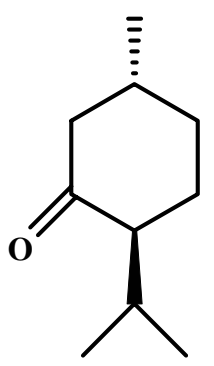

3

\section{Figure 1}

Camphor, fenchone and their derivatives are widely used as primary chirality sources. This is because of the fact that the different position of the gem-dimethyl group in each derivative confers dissimilar topology, often reflected in the capacity of chirality transfer. Therefore, they are often employed as chiral reagents, intermediates or catalysts in asymmetric synthesis. ${ }^{5}$ 
In order to compare the chirality induction by bicyclic versus monocyclic terpenone structures, the reaction was also studied on menthone, which produces satisfactory diastereoisomeric excesses in other types of reactions. ${ }^{6}$

\section{Results and Discussion}

Bearing in mind the above mentioned influence of camphor versus fenchone topology, ${ }^{5}$ we initially attempted the synthesis of the corresponding heterocyclic compounds starting from fenchone thiosemicarbazone 4, and later extended this study to thiosemicarbazones derived from camphor 5 and menthone 6 (see Figure 2).

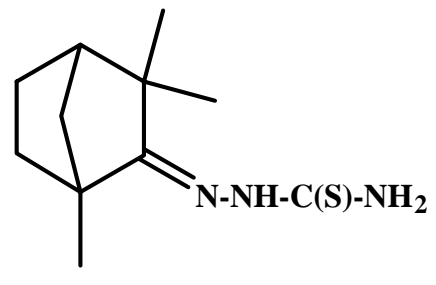

4

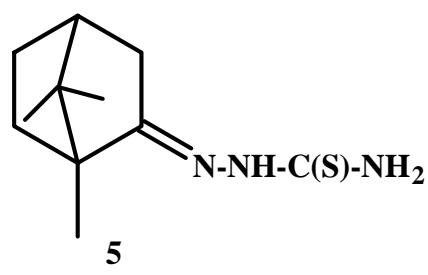

5

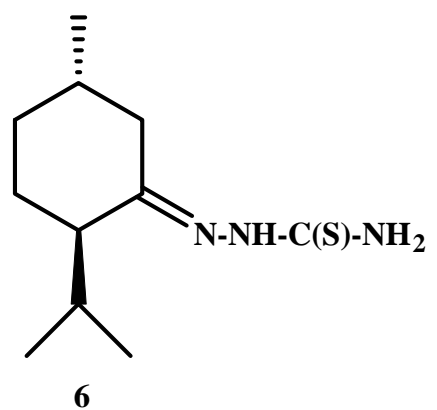

Figure 2

The thiosemicarbazones were synthesized by treatment of the corresponding terpenones with thiosemicarbazide in acid medium, unless otherwise indicated, according to the general procedure previously described. ${ }^{2}$

Treatment of the thiosemicarbazone from fenchone 4, in acetylation conditions with acetic anhydride and pyridine at $110^{\circ} \mathrm{C}$, afforded the spiro thiodiazoline 7 . Thin layer chromatography of the raw reaction product and the study of its ${ }^{1} \mathrm{H}$ - and ${ }^{13} \mathrm{C}-\mathrm{NMR}$ spectra indicated that a single spirane product had been obtained. The spiro structure was clearly demonstrated by the = $100.1 \mathrm{ppm}$ signal in the ${ }^{13} \mathrm{C}$-NMR spectrum assigned to the spiro carbon atom. When the reaction was carried out at low temperature, the same single product was obtained. In order to determine the configuration of the new chiral spiro center, several NMR experiments were required. A two-dimensional (2D)- ${ }^{13} \mathrm{C}$, ${ }^{1} \mathrm{H}$-correlated (HMQC) technique was very useful to assign all carbon and hydrogen atoms of 7. An additional NOESY experiment led us to propose the configuration $\mathbf{R}$ of the new stereogenic center. Figure 3 shows spectroscopic assignment data. 

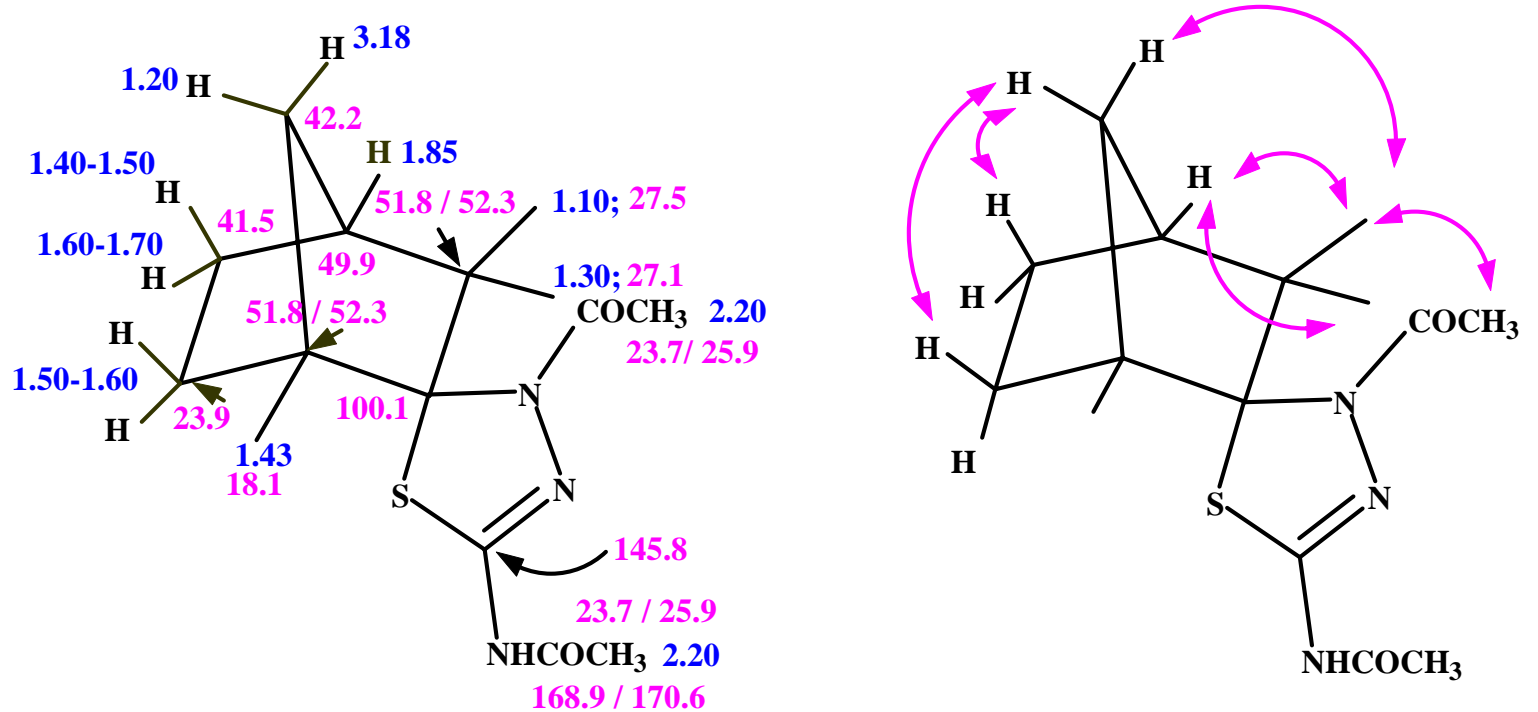

Figure 3. Spectroscopic data of 7.

X-ray diffraction analysis confirmed the assigned configuration $\mathbf{R}$ (Figure 4) and showed that ring closure in the case of 4 takes place by the attack of the sulfur atom from the endo face of the bicyclic structure.

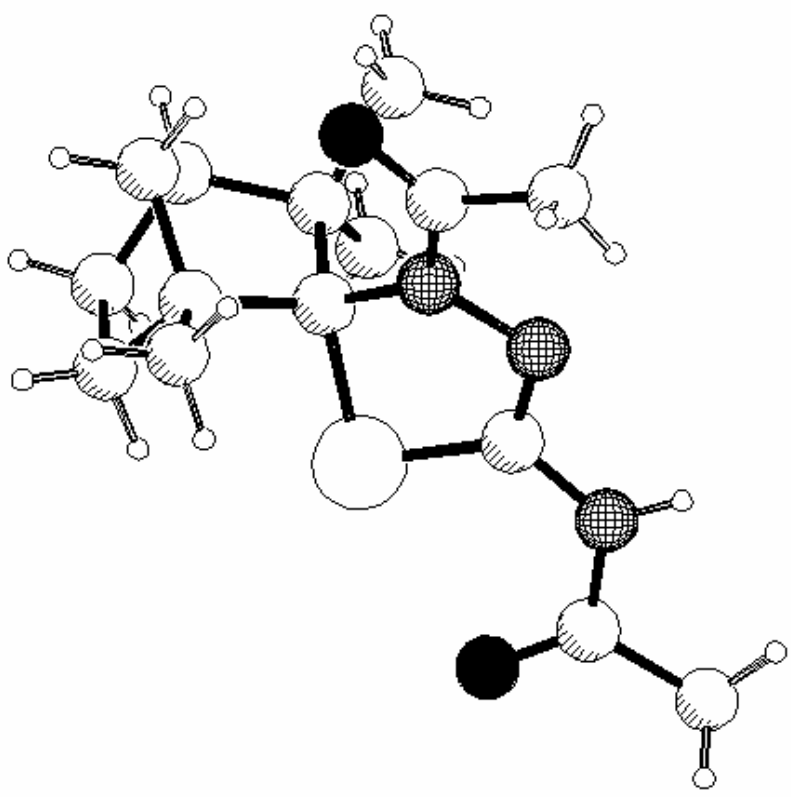

Figure 4. Structure of compound 7 determined by X-ray analysis. 
The highly enantioselective synthesis of thiadiazoline was carried out by Somogyi using camphor thiosemicarbazone 5 as starting material. ${ }^{7}$ As described by the author, cyclization in the camphor derivative occurs from the opposite face (exo), that is to say contrary to what is observed in fenchone; however, no explanation is provided for such assignment. Therefore, to confirm the assignment proposed by Somogyi for the camphor thiadiazoline 8, the latter was synthesized via the corresponding thiosemicarbazone 5, using conditions already described by us. ${ }^{2}$ Spectroscopic analysis of the raw reaction product identified a single spirane compound $(\delta$ $=90.4 \mathrm{ppm}$ in the ${ }^{13} \mathrm{C}-\mathrm{NMR}$ spectrum). Purification and thorough spectroscopic study of the obtained product $\left({ }^{1} \mathrm{H}-{ }^{13} \mathrm{C}-\mathrm{NMR}, \mathrm{COSY}\right.$, HETCOR and NOESY) allowed confirmation of the structure previously proposed by Somogyi.

Bearing in mind the data available from the literature, ${ }^{8}$ the $\mathrm{H}_{3 \mathrm{~b}}$ structure was assigned as the more deshielded $(\delta=3.73 \mathrm{ppm}$ ), whose signal is seen as a doublet (the gem partition alone is observed) since it forms an angle of $90^{\circ}-100^{\circ}$ with hydrogen $\mathrm{H}_{4}$.

The $\mathrm{H}_{3 \mathrm{a}}(\delta=2.09 \mathrm{ppm})$ signal appears in the ${ }^{1} \mathrm{H}$-NMR spectrum superimposed upon the methyl signal $(\delta=2.11 \mathrm{ppm})$ of the $\mathrm{NH}-\mathrm{COCH}_{3}$ group, substituent of the heterocycle.

Relevant NOE effects observed in the NOESY experiment, that allowed confirmation of the configuration of the thiadiazoline structure in the camphor compound 5, are indicated in Figure 5 .
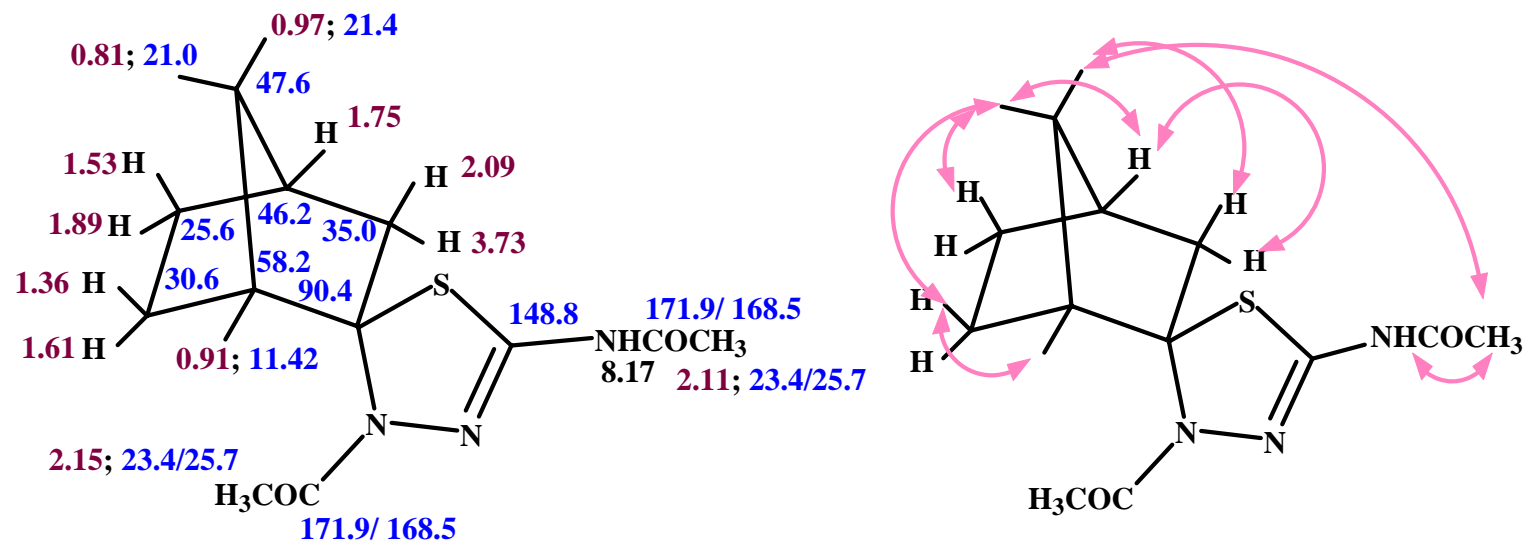

Figure 5. Spectroscopic data of 8.

Such contrasting facial selectivity in the preparation of the thiadiazolines seem due to two main factors: firstly, the dissimilar topology of both bicyclic systems and, secondly, the probable mechanism involved in heterocyclization. The latter requires acetylation of the azomethine nitrogen atom that favors the development of a positive charge on the carbon atom of this group. The bulky (N-Ac) group interacts strongly with diverse parts of the molecule, according to their nature: in the camphor derivative with the gem dimethyl group and in the fenchone derivative with the $\mathrm{H}_{5 \mathrm{~b}}$ and $\mathrm{H}_{6 \mathrm{~b}}$ atoms of the endo face. Thus the thiadiazoline ring closes by the attack of sulfur preferentially by this face (see Scheme 2). 
<smiles>[R]C=NNC([R])=S</smiles>

Scheme 2. Mechanism proposed for the heterocyclation reaction.

Other authors ${ }^{9}$ have also observed that the sulfur atom attacks the $\mathrm{sp}^{2}$ carbon by the more hindered face.

When analyzing the products of the heterocyclization reaction on the thiosemicarbazone of camphor 5, a further product was isolated, resulting from the loss of the thiocarbamoyl group followed by monoacetylation to which the structure 9 was assigned. The fact that no similar product could be found in the reaction on the fenchone derivative is attributable to thegreater hindrance created by the gem dimethyl group of camphor. When repeating the reaction under the conditions proposed by Somogyi, the product 9 resulting from the loss of the carbamoyl group was also obtained in high yield (8:9; 3:2). For NMR data see Figure 6.

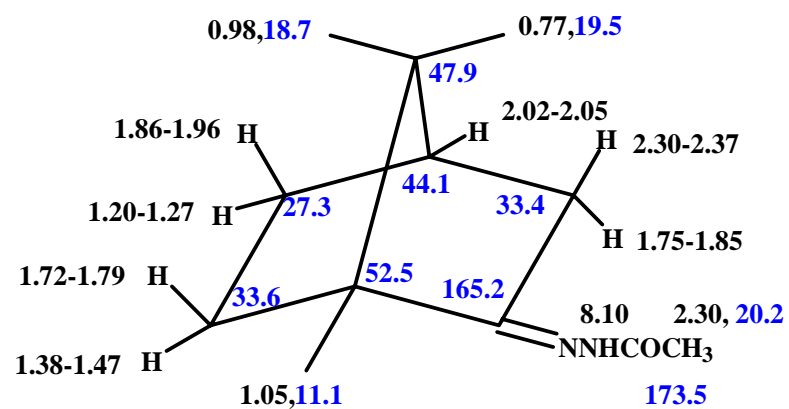

Figure 6. Spectroscopic data of 9.

Finally, the monocyclic terpene ketone menthone 3 was studied in an attempt to compare the effect of the monocyclic system on the diastereoselection, with respect to bicyclic systems. The thiosemicarbazone of menthone $\mathbf{6}$ was thus synthesized under the conditions described. The study of the compounds present in the raw reaction product disclosed three thiosemicarbazones, in disagreement with the two expected products, syn and anti, of the thiosemicarbazones derived from menthone. Since menthone-isomenthone epimerization in acid medium and/or thermally is a well-known fact, ${ }^{8}$ the synthesis of thiosemicarbazone 6 was, therefore, carried out without acid 
catalysis. In this case, a single thiosemicarbazone was isolated from the raw reaction medium, whose treatment under acetylating conditions led to a single thiadiazoline 10. The configuration of the new chiral center of thiadiazoline $\mathbf{1 0}$ was determined by NMR spectroscopy. HETCOR allowed the unequivocally assignment of the carbon and hydrogen atom signals of the product. The marked deshielding observed in hydrogen atoms $2^{\prime}$ and $6^{\prime}(\delta=2.60$ and $\delta=2.80$, respectively) in axial position of the ring derived from menthone is attributable to the anisotropic effect exerted by the carbonyl group of the acetyl moiety linked to the heterocyclic system. The NOE effects observed in the NOESY spectrum allowed the assignment of a probable configuration for the new chiral center as shown in Figure 7.
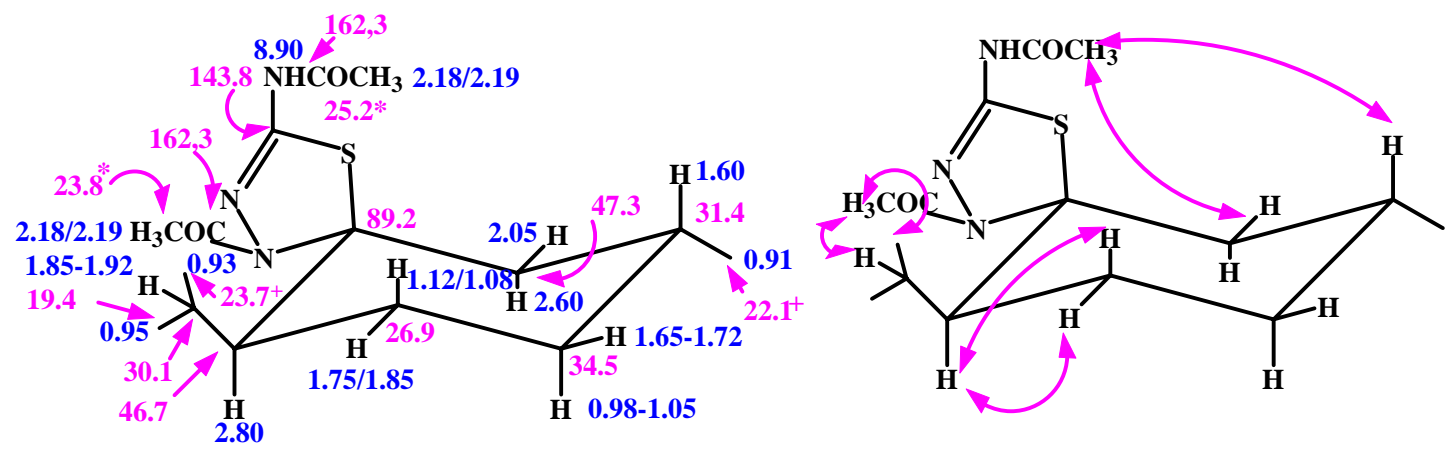

Figure 7. Spectroscopic data of $\mathbf{1 0 .}$

\section{Conclusions}

The versatility and usefulness of terpenones as chiral starting material in enantiospecific synthesis has been once again demonstrated by our present development of an efficient stereocontrolled methodology to prepare a variety of spiro thiadiazolines, despite the fact that the probable mechanism involved in the development of this new chiral center takes place through a carbocation intermediary.

\section{Experimental Section}

General Procedures. Melting points were measured on a Unimelt apparatus and on a Electrothermal IA 9000 apparatus and are uncorrected. IR spectra were measured as mull with a Nicolet IRFT spectrophotometer. Standard ${ }^{1} \mathrm{H}$ and ${ }^{13} \mathrm{C}$ NMR spectra were recorded with a Bruker AC200 instrument at $200 \mathrm{MHz}$ and $50 \mathrm{MHz}$, respectively. Heteronuclear correlation spectroscopy and NOE experiments were determined in a Bruker 400-MHz, and in a Bruker 500$\mathrm{MHz}$ spectrometer. Chemical shifts are reported downfield relative to tetramethylsilane and are expressed in ppm. High-resolution mass spectra (HRMS) were determined in a VG AutoSpec 
(Micromass Inst.). Thin layer chromatography (tlc) and preparative thin layer chromatography (Prep. tlc) were performed with Silica Gel GF 254 (Merck); elution with hexane: ethyl acetate: chloroform (3.5: 2.0: 1.5). The optical rotations were determined, in solution of methylene chloride, with a Perkin Elmer 141 polarimeter.

Fenchone thiosemicarbazone (4). This compound was prepared from the equimolecular quantity of $l$-fenchone and thiosemicarbazide dissolved in ethanol and several drops of $\mathrm{HCl}$ (c). The mixture was heated at reflux (nearly $5 \mathrm{~h}$ ) monitoring the reaction using tlc. Evaporation under reduced pressure gave the corresponding thiosemicarbazone. Recrystallization of the residue from ethanol gave a crystalline solid which was a mixture of two isomers in a $6: 1$ mixture (yield $40 \%$ ); m.p. $167-168{ }^{\circ} \mathrm{C}$.

IR data: $v_{\max }(\mathrm{film}) / \mathrm{cm}^{-1} 3406,3289,3186\left(\mathrm{NH}\right.$ and $\left.\mathrm{NH}_{2}\right), 1610(\mathrm{C}=\mathrm{O}), 1500(\mathrm{C}=\mathrm{N})$ and 1236 $(\mathrm{C}=\mathrm{S})$.

NMR data $\delta_{\mathrm{H}}\left(\right.$ DMSO- $\left.d_{6}\right) 9.40,8.30,7.47\left(3 \mathrm{H}, \mathrm{NH}\right.$ and $\left.\mathrm{NH}_{2}\right), 1.91-1.84(1 \mathrm{H}, \mathrm{m}), 1.70-1.61(2 \mathrm{H}$, m), 1.55-1.49 (2H, m), 1.39-1.34 (2H, d, $J=12 \mathrm{~Hz}), 1.26(3 \mathrm{H}, \mathrm{s}), 1.19(1 \mathrm{H}, \mathrm{s}), 1.17(1 \mathrm{H}, \mathrm{s}), 1.06-$ $1.09(1 \mathrm{H}, \mathrm{d}, J=12 \mathrm{~Hz}) . \delta_{\mathrm{C}}\left(\mathrm{DMSO}-d_{6}\right) 177.9(\mathrm{C}=\mathrm{S}), 168.4(\mathrm{C}=\mathrm{N}), 50.9(\mathrm{C}-3$ or C-1), $49.0(\mathrm{C}-4)$, 42.6 (C-3 or C-1), 42.0 (C-7), 33.8 (C-5), 24.5 (C-6), 22.7 (C-8 or C-9), 22.4 (C-8 or C-9), 16.9 (C-10).

Exact mass Calcd.: 226.13780. Found: 226.13754.

Camphor thiosemicarbazone (5). This compound was prepared from the equimolecular quantity of rac-camphor and thiosemicarbazide dissolved in ethanol and several drops of $\mathrm{H}_{2} \mathrm{SO}_{4}$ (c). The mixture was heated at reflux (nearly $5 \mathrm{~h}$ ) monitoring the reaction using tlc. Evaporation under reduced pressure gave the corresponding thiosemicarbazone. This compound was recrystallized from ethanol and water $(3: 2)$ (yield $85 \%$ ); m.p. $147-150{ }^{\circ} \mathrm{C}\left(\right.$ lit $^{7} 154-155^{\circ} \mathrm{C}$ ).

IR data: $v_{\max }($ film $) / \mathrm{cm}^{-1} 3443,3237$ and $3149(\mathrm{NH}), 1588(\mathrm{C}=\mathrm{N}), 1515\left(\mathrm{~S}=\mathrm{C}-\mathrm{NH}_{2}\right)$ and 1250 $\left(\mathrm{S}=\mathrm{C}-\mathrm{NH}_{2}\right)$. NMR data: $\delta_{\mathrm{H}}\left(\mathrm{CDCl}_{3}\right) 9.80,8.00,7.40\left(3 \mathrm{H}, \mathrm{NH}_{2}\right.$ and $\left.\mathrm{NH}\right), 2.00-1.93(1 \mathrm{H}, \mathrm{m}, \mathrm{H}-4)$, 2.45-2.31 (1H, m, H-3 exo), 2.06-2.00 (1H, m, H-3 endo), 1.85-1.80 (1H, m, H-5 exo), 1.25-1.12 (1H, m, H-5 endo), 1.70-1.67 (1H, m, H-6 exo), 1.40-1.30 (1H, m, H-6 endo), 0.97 (3H, s, H10), $0.93(3 \mathrm{H}, \mathrm{s}, \mathrm{H}-9), 0.73(3 \mathrm{H}, \mathrm{s}, \mathrm{H}-8) . \delta_{\mathrm{C}}\left(\mathrm{CDCl}_{3}\right) 166.8(\mathrm{C}=\mathrm{N}), 168.4(\mathrm{C}=\mathrm{S}), 52.8(\mathrm{C}-1), 48.1$ (C-7), 43.9 (C-4), 32.4 and 33.8 (C-3 and C-6 exchangeable), 27.1 (C-5), 19.4 (C-8 or C-9), 18.6 (C-8 or C-9), 11.0 (C-10).

Menthone thiosemicarbazone (6). This compound was prepared from equimolecular quantity of $l$-menthone and thiosemicarbazide dissolved in ethanol. The mixture was heated at reflux monitoring the reaction using tlc. Precipitation with water gave the corresponding thiosemicarbazone. This compound was recrystallized from ethanol and water (3:2) (yield 99\%); m.p. $135-137^{\circ} \mathrm{C} ;[\alpha]_{\mathrm{D}}-11.2^{\circ}(c=0.5)$.

IR data $v_{\max }($ film $) / \mathrm{cm}^{-1} 3443,3244$ and $3156(\mathrm{NH}), 1588(\mathrm{C}=\mathrm{N}), 1499\left(\mathrm{~S}=\mathrm{C}-\mathrm{NH}_{2}\right)$, and 1300 $\left(\mathrm{S}=\mathrm{C}-\mathrm{NH}_{2}\right)$.

NMR data $\delta_{\mathrm{H}}\left(\mathrm{DMSO}-\mathrm{d}_{6}\right) 10.25,8.06,7.21\left(3 \mathrm{H}, \mathrm{NH}_{2}\right.$ and $\left.\mathrm{NH}\right), 2.95-2.85(1 \mathrm{H}, \mathrm{m}), 2.30-2.10$ $(1 \mathrm{H}, \mathrm{m}), 1.98-1.80(3 \mathrm{H}, \mathrm{m}), 1.55-1.40(1 \mathrm{H}, \mathrm{m}), 1.25-1.07(1 \mathrm{H}, \mathrm{m}), 1.05-0.85(8 \mathrm{H}$, complex 
signal), 0.80-0.60 (3H, d). $\delta_{\mathrm{C}}\left(\mathrm{DMSO}_{-} \mathrm{d}_{6}\right) 178.8(\mathrm{C}=\mathrm{S}), 157.9(\mathrm{C}=\mathrm{N}), 49.8,34.9,33.1,32.5,27.3$, 25.9, 21.7, 21.3, 19.0.

Exact mass Calcd.: 228.15345. Found: 228.15283.

\section{General procedure for synthesis of thiadiazolines}

Thiosemicarbazone $(0.25 \mathrm{mmol})$ was dissolved in $0.5 \mathrm{~mL}$ of pyridine and $0.5 \mathrm{~mL}$ of acetic anhydride and the mixture was heated at $110^{\circ} \mathrm{C}$ during $1.50 \mathrm{~h}$ with magnetic stirring. The crude product was purified by tlc eluting with hexane:ethyl acetate:chloroform (3.5:2.0: 1.5) or by recrystallization as is indicated in each case.

Fenchone thiadiazoline (7). Compound 7 was obtained from fenchone thiosemicarbazone 4. This compound was recrystallized from ethanol (yield $58 \%$ ); m.p. $186-187{ }^{\circ} \mathrm{C} ;[\alpha]_{\mathrm{D}} 383.0$ $(c=0.75)$

IR data: $v_{\max }\left(\right.$ film) $/ \mathrm{cm}^{-1}$ 3289(NH), $1712(\mathrm{C}=\mathrm{O}), 1668(\mathrm{C}=\mathrm{O}), 1632(\mathrm{C}=\mathrm{N})$ and 1394.

NMR data: $\delta_{\mathrm{C}}$ and $\delta_{\mathrm{H}}\left(\mathrm{CDCl}_{3}\right)$ : see figures 3 .

Exact mass Calcd.: 310.15958. Found: 310.15943.

\section{X-Ray diffraction analysis of 7}

Suitable crystals were obtained by crystallization from DMSO. Crystal dimensions: 0.72 x $0.29 \mathrm{x}$ $0.22 \mathrm{~mm}$. Empirical formula $\mathrm{C}_{15} \mathrm{H}_{23} \mathrm{~N}_{3} \mathrm{O}_{2} \mathrm{~S}$. Molecular weight 309.42. Crystal system: orthorhombic. Space group P $2{ }_{1} 2_{1} 2_{1}\left(\mathrm{~N}^{0} 19\right)$. Lattice parameters: $a=9.757(3) \AA, b=12.043(2) \AA$, $c=13.876(3) \AA, \mathrm{V}=1630.5(7) \AA^{3} . \mathrm{Z}=4$. Calculated density $1.261 \mathrm{~g} \mathrm{~cm}^{-3} . \mathrm{F}(000)=664$. Data were collected at 293(2) $\mathrm{K}$ on an Enraf Nonius CAD4 diffractometer using MoKa radiation $(\lambda=0.71069 \AA)$ yielding 1431 independent reflections. The structure was solved by direct methods (SHELXS-86) ${ }^{10}$ and refined by least-squares on $\mathrm{F}^{2}$ for all reflections (SHELXL-97). ${ }^{11}$ Non-hydrogen atoms were refined anisotropically. The hydrogen atom bonded to nitrogen was located on a difference Fourier map and refined isotropically. Hydrogen atoms bonded to carbon were placed in calculated positions with isotropic displacement parameters 1.5 (methyl H) or 1.2 (the rest) times the $U_{\text {eq }}$ values of corresponding carbons. Refined parameters 194. Goodness-offit on $\mathrm{F}^{2}: 1.067$. $\mathrm{R}(\mathrm{F})=0.035$ for reflections with $\mathrm{I}>2 \sigma(\mathrm{I}), \mathrm{R}_{\mathrm{w}}\left(\mathrm{F}^{2}\right)=0.101$ for all data.

Camphor thiadiazoline (8). Compound 8 was obtained from camphor thiosemicarbazone 5. This compound was purified by prep. tlc (yield 30\%), Rf: 0.55 ; m.p. 160-162 ${ }^{\circ} \mathrm{C}$. lit. ${ }^{7}: 161{ }^{\circ} \mathrm{C}$. IR data: $v_{\max }($ film $) / \mathrm{cm}^{-1}$ 3250, $3170(\mathrm{NH}), 1700(\mathrm{C}=\mathrm{O}), 1670(\mathrm{C}=\mathrm{O}), 1630(\mathrm{C}=\mathrm{N})$ and 1410 . NMR data: $\delta_{\mathrm{C}}$ and $\delta_{\mathrm{H}}\left(\mathrm{CDCl}_{3}\right)$ : see figure 5 .

$\boldsymbol{N}$-[Aza(1,7,7-trimethylbicyclo[2.2.1]hept-2-ylidene)methyl]acetamide (9). Compound 9 was obtained from camphor thiosemicarbazone 5 as another fraction of the prep. tlc (yield 20\%), Rf: 0.35 ; m.p. $186-188^{\circ} \mathrm{C}$.

IR data $v_{\max }($ film $) / \mathrm{cm}^{-1} 3200(\mathrm{NH}), 1688(\mathrm{C}=\mathrm{N}), 1620,1373(\mathrm{~N}-\mathrm{CO})$.

NMR data: $\delta_{\mathrm{C}}$ and $\delta_{\mathrm{H}}\left(\mathrm{CDCl}_{3}\right)$ : see figure 6

Exact mass Calcd.: 209.16539. Found: 209.16524. 
Menthone thiadiazoline (10). Compound 10 was obtained from menthone thiosemicarbazone 6. This compound was purified by prep. tlc (yield 45\%); m.p. $167-170{ }^{\circ} \mathrm{C} ;[\alpha]_{\mathrm{D}}-6.4^{\circ}(c=1)$. IR data: $v_{\max }($ film $) / \mathrm{cm}^{-1} 3259(\mathrm{NH}), 1719(\mathrm{C}=\mathrm{O}$ amide), $1685(\mathrm{C}=\mathrm{O}$ amide $), 1650(\mathrm{~N}-\mathrm{CO})$, and $1631(\mathrm{C}=\mathrm{N})$ y $1580(\mathrm{C}=\mathrm{N})$;

NMR data: $\delta_{\mathrm{C}}$ and $\delta_{\mathrm{H}}\left(\mathrm{CDCl}_{3}\right)$ : see figure 7

Exact mass Calcd:: 311.16675. Found: 311.16660.

\section{Acknowledgments}

Financial support of this work by Universidad de Buenos Aires, Agencia Nacional de Promoción Científica y Tecnológica and Consejo Nacional de Investigaciones Científicas y Técnicas (CONICET) is warmly acknowledged. The authors thank Dr. Teodor Parrella, Dr Mirta Fascio and Instituto Nacional de Tecnologia Industrial for their NMR support.

\section{References}

1. Popov, S. A.; Denisov, A. Y.; Gatilov,Y. V.; Bagryanskaya I. Y.; Tkachev, A. V. Tetrahedron Asymmetry 1994, 5, 479.

2. Martins Alho, M. A.; Moglioni, A. G.; Brousse, B.; Moltrasio Iglesias G. Y.; D'Accorso N. B. ARKIVOC hptt://www.arkat.org/journal/Issue4/ms0062/ms0062.htm, 2000, 1 (4), 627.

3. (a) Blumenkopf, T. A.; Harrington, J. A.; Koble, C. S.; Bankston, D. D.; Morrison, R.W. Jr.; Bigham, E. C.; Styles, V. L.; Spector, T. Journal of Medicinal Chemistry 1992, 35, 2306. (b) Sidwell, R. W.; Huffman, J. H.; Schafer, T. W.; Shipman, C. Chemotherapy 1990, 36, 58. (c) Teitz, Y.; Ronen, D.; Vansover, A.; Stematsky, T.; Riggs, J. L. Antiviral Research 1994, 24, 305. (d) Ali, S.; Alam, M. Archives of Pharmaceutical Research 1994, 17, 131.

4. (a) Martins Alho, M. A.; D'Accorso, N. B. J. Heterocyclic Chem. 2000, 37, 811. (b) Martins Alho, M. A.; D'Accorso N. B. Carbohydr. Res. 2000, 328, 481.

5. Oppolzer, W. Tetrahedron 1987, 1969.

6. Aitken R. A.; Kilényi S. N. Asymmetric Synthesis, Blackie Academic \& Professional, Glasgow, 1992.

7. Somogyi, L. Liebigs Ann.Chem. 1991, 1267.

8. Gamble, D. L.; Hems, W. P.; Ridge B. J. Chem. Soc., Perkin Trans. I 2001, 248.

9. Shamsuzzaman, M. A.; Anwar, S. J. Chem. Res. 1998, 824.

10. Sheldrick, G. M. SHELXS-86. Crystallographic Computing 3. Sheldrick, G. M.; Krüger, C.; Goddard, R. Eds.; Oxford University Press: Oxford, 1985.

11. Sheldrick, G. M. SHELXL-97. Program for the Refinement of Crystal Structures, Göttingen, 1997. 